Open Access

\title{
Dorsal and medial raphe nuclei participate differentially in reproductive functions of the male rat
}

\author{
María E. Ayala ${ }^{1 *}$, Diana E. Velázquez ${ }^{1}$, Juan L. Mendoza ${ }^{1}$, Juana Monroy ${ }^{1}$, Roberto Domínguez ${ }^{1}$, \\ Mario Cárdenas ${ }^{2}$ and Andrés Aragón $n^{3,4}$
}

\begin{abstract}
Background: Innervation of the hypothalamus and median eminence arise from the dorsal and medial raphe nuclei (DRN and MRN, respectively). The hypothalamus regulates the secretion of gonadotropins, which in turn regulate the reproductive function of males and females. However, it is not known the role of raphe nuclei in male reproductive function. Our goal was to investigate the role of the DRN and MRN in the regulation of the testicular function and secretion of gonadotropins in prepubertal rats.

Methods: Dihydroxytryptamine (5,6-DHT) in ascorbic acid was used to chemically lesion the DRN or MRN. Rats were treated at 30 days-of-age and sacrificed at 45 or 65 days-of-age. Sham-treated controls were injected with ascorbic acid only. Negative controls were untreated rats. The damage induced by the 5,6-DHT was monitored in coronal serial sections of DRN and MRN; only the animals in which lesion of the DRN or MRN was detected were included in this study. As output parameters, we measured the concentrations of noradrenaline (NA), dopamine (DA) and serotonin $(5-\mathrm{HT})$ in the anterior $(\mathrm{AH})$ and medial $(\mathrm{MH})$ hypothalamus by high performance liquid chromatography (HPLC); whereas, circulating concentrations of gonadotropins and sexual steroids were measured by radioimmunoassay. Seminiferous epithelium and sperm quality were also evaluated.
\end{abstract}

Results: Lesion of DRN or MRN does not induced changes in concentrations of LH, progesterone, and testosterone. Compared with the control group, the sham or lesion of the DRN or MRN did not modify noradrenaline or dopamine concentrations in the $\mathrm{AH}$ and $\mathrm{MH}$ at 45 or 65 days of age. Meanwhile, serotonin concentrations decreased significantly in lesioned rats. Lesion of DRN induced significantly lower concentrations of FSH regardless of age; similar lesion in the MRN had no impact on FSH levels. Sperm concentration and motility were significantly decreased in the same animals. The lesion of the MRN does not induced changes in the seminiferous epithelium or gonadotropin levels. Our results suggest that raphe nuclei regulate differentially the male reproductive functions.

Conclusions: The DRN but not the MRN regulates the secretion of gonadotropins and testicular function.

Keywords: Serotonin, hypothalamus, gonadotropin, seminiferous epithelium, sperm

\footnotetext{
* Correspondence: marayalamx@yahoo.com.mx

María E. Ayala and Andrés Aragón are Joint Senior Authors.

'Unidad de Investigación en Biología de la Reproducción, Laboratorio de

Pubertad, Facultad de Estudios Superiores Zaragoza, UNAM. AP 9-020, CP

15000, Distrito Federal, México

Full list of author information is available at the end of the article
} 


\section{Background}

The regulation of testicular function depends on the integration of neuroendocrine mechanisms that involve the hypothalamus-hypophysis axis [1]. Gonadotropins FSH and LH, secreted by the hypophysis, regulate spermatogenesis. Gonadotropin secretion is modulated by gonadotropin releasing hormone $(\mathrm{GnRH})$, which is produced by the hypothalamus [2]. Furthermore, the neural information from extrahypothalamic areas, such as the DRN and MRN raphe nuclei, regulates the secretion of gonadotropins in adult female [3-6] and male [7-9] rats.

Ascending serotonergic projections from the DRN and MRN innervate the hypothalamus and median eminence [8, 10-12] and synapses with GnRH neurons, suggesting the participation of serotonin on $\mathrm{GnRH}$ and gonadotropin secretion [13-15]. In adult male rats, LH secretion is unchanged after sectioning of fibers arising from the MRN. In contrast, $\mathrm{LH}$ secretion decreases after sectioning of fibers arising from the DRN [7], or increases following chemical lesion by injection of 5,7-dihydroxytryptamine (5,7-DHT) into the DRN [9]. These results cannot be attributed solely to the serotonergic system, because the DRN and MRN contain both serotonergic and nonserotonergic neurons [16-18]. Furthermore, 5,7-DHT is a non-specific neurotoxin, as it damages both serotonergic and noradrenergic neurons [19].

In the female, the serotonergic system, arising from the DRN and MRN, differentially participates in the regulation of gonadotropin secretion. This can be attributed to the complexity of these nuclei, because serotonergic neurons from the DRN and MRN exhibit distinct anatomical, electrophysiological, and functional properties [20-23]. These distinct features suggest different functional roles for the two serotonergic systems. Despite increased interest in the functional properties of these individual raphe nuclei, very little is known about the participation of the serotonergic system, originating from the raphe nuclei, in the regulation of testicular function in the adult male rat. Furthermore, no information exists on the participation of these nuclei during puberty in the male rat.

Some derivates of amphetamine exert differential neurotoxic effects on the serotonergic neurons from the DRN and MRN; the serotonergic neurons from the DRN are more affected than MRN cells [20, 21, 24]. The neurotoxic effects of these drugs on serotonergic neurons are related to the formation of toxic metabolites, such as 5,6-dihydroxytryptamine (5,6-DHT) [21, 25-27].

The objective of this work was to investigate the role of the serotonergic system from the DRN and MRN on the secretion of gonadotropins and reproductive function of male rats. We achieved our objective by lesioning, with 5,6-DHT, the serotonergic neurons of the raphe nuclei and evaluating the circulating gonadotropins and sexual steroids, seminiferous epithelium, and sperm quality.

\section{Materials and Methods}

\section{Experimental strategy}

Male rats of the CII-ZV strain $(n=160)$, from our own breeding stock, were maintained under controlled light conditions (lights on from 05:00 to 19:00), with free access to food and tap water. We allocated animals randomly to one of three groups described below. At 30 days of age, the MRN or DRN of prepuberal male rats was chemically lesioned. All animals were sacrificed at 45 or 65 days of age, 15 or 35 days after lesion, circulating concentrations of sexual steroids and gonadotropins, seminiferous epithelium, and sperm quality were evaluated.

Rationales for use of prepuberal animals and schedule of sampling were the permissive role of serotonin toward pubertal maturation, the age at which spermatogenesis is completed in the testis, and the time required for the sperm traverse the epididymis.

\section{Ethical approval}

We conducted all experiments in strict accordance with the Mexican Law of Animal Treatment and Protection Guidelines. The Institutional Ethics Committee of the Facultad de Estudios Superiores Zaragoza, Universidad Nacional Autónoma de México approved the protocol (Letter date 01/03/2012).

\section{Control Group}

The animals were untreated.

\section{Lesioned groups}

Animals were anesthetized with sodium pentobarbital (Anestesal, Smith Kline Norden of Mexico, Monterrey Nuevo León; $35 \mathrm{mg} \mathrm{kg}^{-1}$ of body weight, i.p.) and placed in a stereotaxic apparatus. The head skin was opened, the skull drilled and a number 29-needle (13 $\mathrm{mm}$ long) introduced following parameters of the stereotaxic atlas by Paxinos and Watson [28]. Coordinates for the DNR are: $\mathrm{AP}=0.7 \mathrm{~mm}$ from lambda, $\mathrm{H}=$ $3.3 \mathrm{~mm}$, and $\mathrm{L}=6.4 \mathrm{~mm}$ at a $30^{\circ}$ angle in relation to its perpendicular axis from the dorsal raphe. For MRN: $\mathrm{AP}=0.5 \mathrm{~mm}, \mathrm{H}=4.9 \mathrm{~mm}$, and $\mathrm{L}=8.0 \mathrm{~mm}$ at a $35^{\circ}$ angle in relation to its perpendicular axis. To produce the lesion of the DRN or the MRN, the needle was connected via tubing to a $100 \mu \mathrm{l}$ Hamilton syringe mounted on a microinjection pump (MCA/100 Bionalytical Systems, Inc., West Lafayette, In, USA). $10 \mu \mathrm{g}$ of 5,6-DHT (Sigma Chemical Co., St Louis, Mo, USA) dissolved in $2.5 \mu \mathrm{l}$ of $0.05 \%$ ascorbic acid ( $\mathrm{pH} 3.5$ ) was injected at an infusion rate of $1 \mu \mathrm{l} / \mathrm{min}$. 5,6-DHT is a serotonergic-specific neurotoxin [6]. The 5,6-DHT dose was selected based on previous experiments, because $10 \mu \mathrm{g}$ generated a selective depletion of serotonin concentration in the hypothalamus (50 \%) but does not impact catecholamine concentration [29]. 


\section{Sham-operated groups}

Animals were treated with the same parameters used in the lesion groups, but were injected with $2.5 \mu \mathrm{l}$ of $0.05 \%$ of ascorbic acid; lesion of the DRN or the MRN.

\section{Autopsy Procedure}

The animals were killed by bleeding under ether anesthesia. The brain was quickly removed and placed in cold saline solution and frozen in liquid nitrogen. After careful removal of the nerves and optic chiasm, the anterior and medium hypothalamus were dissected following the parameters described previously [28]. The anterior hypothalamus (Bregma 20.8 to Bregma 21.8) included the removal of the lateral and median pre-optic nuclei, the suprachiasmatic, the paraventricular, the periventricular, and the stria terminal pre-optic area. The medial hypothalamus (Bregma 22.3 to Bregma 23.2) included the median eminence and arcuate nucleus. Both hypothalamic regions were stored at $-70{ }^{\circ} \mathrm{C}$, until the concentrations of serotonin, and its metabolite 5-HIAA, were measured using HPLC.

Blood was collected from the trunk of the animals, allowed to clot, and subsequently centrifuged at $3000 \mathrm{rpm}$. The serum supernatant was collected and stored at $-20^{\circ} \mathrm{C}$. We measured progesterone, testosterone, $\mathrm{LH}$, and FSH levels as described below. The testes, epididymis, prostate, and seminal vesicles were dissected and individually weighed on a precision balance.

\section{Measurement of serotonin, noradrenaline, and dopamine} The amounts of serotonin (5-HT), noradrenaline (NA), and dopamine (DA), were measured using the methodology described by Monroy et al. [6]. Briefly, tissue samples were weighed and homogenized in $300 \mu \mathrm{l}$ of $0.1 \mathrm{~N}$ perchloric acid and subsequently centrifuged at $12500 \mathrm{rpm}$ for $30 \mathrm{~min}$ at $-4{ }^{\circ} \mathrm{C}$. The supernatant was filtered using $0.2 \mu \mathrm{m}$ regenerated cellulose filters, and $20 \mu \mathrm{l}$ of this extract was injected into the high-performance liquid chromatography system for analysis. The results are expressed as $\mathrm{ng} / \mathrm{mg}$ of weight of tissue.

\section{Hormone determination}

Serum concentrations of progesterone and testosterone were measured by specific radioimmunoassay (RIA), using kits purchased from Diagnostic Products (Los Angeles, CA, USA). The intra- and inter-assay coefficients of variation were 5.3 and $9.87 \%$ for progesterone and 4.3 and $7.8 \%$ for testosterone. The detection limits for progesterone and testosterone were 0.09 and $0.005 \mathrm{ng} / \mathrm{ml}$, respectively. The results are expressed as $\mathrm{ng} / \mathrm{ml}$.

Concentrations of LH and FSH were measured by RIA, with the reagents and protocol supplied by the National Hormone and Pituitary Programs (Baltimore, MD, USA). The values are expressed in $\mathrm{ng} / \mathrm{ml}$ in terms of the reference preparations of NIH LH-RP2 and FSH-RP2. The intra- and inter-assay coefficients of variation were $7.91 \%$ and $5.74 \%$ for LH and 9.3 and $6.82 \%$ for FSH. The detection limits for LH and FSH were 0.05 and $0.01 \mathrm{ng} / \mathrm{ml}$, respectively.

\section{Sperm quality}

Evaluation of sperm quality was performed in animals of 65 days-of-age, because at this age male rats have mature sperm present in the vas deferens. The content of vas deferens was obtained and placed in $2 \mathrm{ml}$ of Tyrode's salt solution (Sigma Chemical Co., St Louis, Mo, USA) at $37^{\circ} \mathrm{C}$ and gently mixed to homogenize the suspension. A drop of the sperm suspension was placed on a slide for evaluation of motility. For each animal, 200 spermatozoa were analyzed [30, 31] at $100 \mathrm{x}$ total magnification using a phase-contrast microscope (Nikon, Tokyo, Japan). The percentage of motile sperm was defined as the ratio of cells showing movement to the total number of cells $\mathrm{x}$ 100. Sperm viability was determined using $1 \%$ trypan blue (Sigma Chemical Co., St Louis, Mo, USA) following the technique described [30] and 200 cells were analyzed for each animal; results are expressed as percentage of viability. Sperm concentration was determined in a Neubauer chamber (PROPER Lumycite, 1/100 $\mathrm{mm}$ depth), results are presented as $1 \times 10^{6}$ cells $/ \mathrm{ml}$.

\section{Analysis of seminiferous epithelium}

The right testis of each animal was fixed by immersion in Bouin solution, followed by dehydration and embedding in paraffin wax. Serial $10 \mu \mathrm{m}$ sections were obtained and stained with periodic acid Schiff (PAS)-hematoxylin.

From each animal, fifty seminiferous tubules, approximately round, were taken randomly and two diameters were measured: the maximum diameter, and the diameter perpendicular to the maximum. The following formula was used to estimate the area: area $=\pi r^{2}$, where $r=$ (diameter one + diameter two)/4. Results are presented as mean $\pm \mathrm{sd}$ of area in each experimental group.

Staging was realized for each tubule evaluated for area; it was realized by following the development of the acrosome, as reported previously [32]. Each tubule staged was searched for gross histopathological changes. Results are presented as mean \pm se, of percentage from each stage of seminiferous epithelium, in each experimental group.

\section{Brain histology}

After dissecting the hypothalamus, the caudal portion of the brain was fixed in $10 \%$ formalin for at least $48 \mathrm{~h}$. Brains were frozen and sectioned serially at $40 \mu \mathrm{m}$ in the coronal plane using a cryostat kept at $-20{ }^{\circ} \mathrm{C}$. The sections were placed on glass slides and later stained with cresyl violet (Sigma Chemical Co., St Louis, Mo, USA) to confirm the trajectory of the needle, location of the injection site (Fig. 1a, b), and extent of the lesion. Based on the histological 


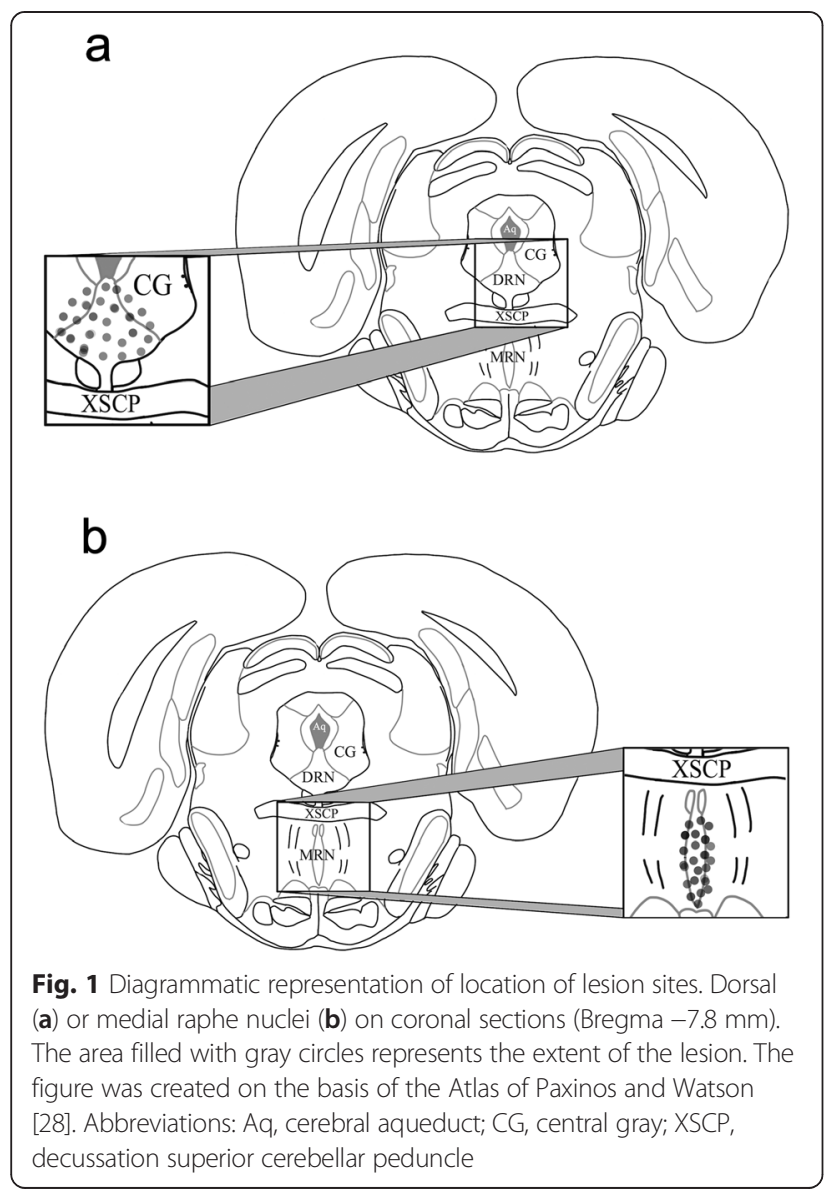

examination of the lesions, only animals with complete lesion of the DRN or MRN were included in this study.

The lesion of the DRN or MRN was determined by light microscopy. The damaged area was unstained, while the healthy tissue was stained violet.
The lesion of the DRN or MRN (Fig. 1) was considered complete when the injured area included the rostral and medial region of the nucleus, and the caudal region was not affected. Also, the dorsal, ventral, and lateral subdivisions of the nucleus were damaged with less destruction of the adjacent area, the substantia grisea periventricularis.

\section{Statistical analysis}

The normality of the data was corroborated graphically in different experiments by checking residuals. The body and organ weights, sperm motility, sperm viability, serum concentration of hormones, as well as serotonin, noradrenaline and dopamine concentrations were analyzed by two-way ANOVA, considering chemical treatment as factor and age of animals as block. Tukey test was used as post hoc test. Proportions of stages of seminiferous epithelium, among treatments, were tested for independence by Pearson Chisquared test. Comparison of the area of seminiferous tubules, in each stage of cycle of seminiferous epithelium, was realized by one way ANOVA for unbalanced models, followed by linear contrast of means. The results were considered significant at the $P<0.05$ level. All analysis were realized with R version 3.1.2 [33] and packages car [34], vcd [35-37], rattle [38], and lattice [39], running on a MacBook with MacOsX version 10.10.1.

\section{Results}

\section{Effects of the sham operation on the DRN or MNR}

Compared to the control group, sham operations to the DRN or MRN did not modify the body, testis, prostate, or seminal vesicle weight (Table 1), nor the noradrenaline and dopamine concentrations in the anterior and medial hypothalamus of animals at either 45 or 65 days-of-age (Table 2). Similarly, no significant differences were observed on the 5 -HT concentrations in the anterior or

Table 1 Effects of chemical lesion of the DRN or MRN raphe nuclei on body weight and sexual accesory glands (grams) (Mean \pm S.E.M.)

\begin{tabular}{|c|c|c|c|c|c|c|}
\hline Group & & $\mathrm{n}$ & Body Weight & Testis & Prostate & Seminal Vesicle \\
\hline \multicolumn{7}{|c|}{45 Days } \\
\hline & Control & 16 & $161 \pm 5.3$ & $0.847 \pm 0.06$ & $0.19 \pm 0.04$ & $0.17 \pm 0.08$ \\
\hline & Sham DRN & 20 & $157 \pm 3.4$ & $0.829 \pm 0.02$ & $0.14 \pm 0.01$ & $0.08 \pm 0.01$ \\
\hline & Lesion DRN & 14 & $153 \pm 3.7$ & $0.771 \pm 0.06$ & $0.09 \pm 0.01$ & $0.06 \pm 0.08$ \\
\hline & Sham MRN & 11 & $155 \pm 4.2$ & $0.739 \pm 0.08$ & $0.16 \pm 0.05$ & $0.07 \pm 0.01$ \\
\hline & Lesion MRN & 10 & $159 \pm 4.5$ & $0.718 \pm 0.09$ & $0.17 \pm 0.08$ & $0.07 \pm 0.02$ \\
\hline \multicolumn{7}{|c|}{65 Days } \\
\hline & Control & 22 & $256 \pm 4.3$ & $1.426 \pm 0.02$ & $0.28 \pm 0.02$ & $0.35 \pm 0.01$ \\
\hline & Sham DRN & 20 & $267 \pm 3.4$ & $1.481 \pm 0.03$ & $0.23 \pm 0.02$ & $0.30 \pm 0.02$ \\
\hline & Lesion DRN & 22 & $250 \pm 5.9$ & $1.403 \pm 0.04$ & $0.22 \pm 0.02$ & $0.25 \pm 0.02$ \\
\hline & Sham MRN & 10 & $267 \pm 10.6$ & $1.443 \pm 0.03$ & $0.36 \pm 0.05$ & $0.31 \pm 0.02$ \\
\hline & Lesion MRN & 15 & $277 \pm 4.1$ & $1.521 \pm 0.03$ & $0.37 \pm 0.19$ & $0.35 \pm 0.01$ \\
\hline
\end{tabular}


Table 2 Effects of chemical lesion of the DRN or MRN raphe nuclei on neurotransmitters concentrations ( $\mathrm{ng} / \mathrm{mg}$ tissue) (Mean \pm S.E.M.)

\begin{tabular}{|c|c|c|c|c|c|c|}
\hline \multirow[b]{2}{*}{ Age } & \multirow[b]{2}{*}{ Group } & \multirow[b]{2}{*}{$n$} & \multicolumn{2}{|l|}{ Anterior } & \multicolumn{2}{|l|}{$\underline{\text { Medial }}$} \\
\hline & & & NA & DA & NA & DA \\
\hline \multicolumn{7}{|c|}{45 Days } \\
\hline & Control & 11 & $1.48 \pm 0.08$ & $0.37 \pm 0.14$ & $1.05 \pm 0.07$ & $0.35 \pm 0.06$ \\
\hline & Sham DRN & 11 & $1.44 \pm 0.09$ & $0.32 \pm 0.01$ & $1.10 \pm 0.07$ & $0.34 \pm 0.05$ \\
\hline & Lesion DRN & 12 & $1.38 \pm 0.18$ & $0.33 \pm 0.15$ & $1.33 \pm 0.14$ & $0.35 \pm 0.04$ \\
\hline & Sham MRN & 6 & $1.36 \pm 0.17$ & $0.28 \pm 0.05$ & $1.37 \pm 0.13$ & $0.43 \pm 0.09$ \\
\hline & Lesion MRN & 6 & $1.47 \pm 0.11$ & $0.31 \pm 0.06$ & $1.16 \pm 0.17$ & $0.40 \pm 0.09$ \\
\hline \multicolumn{7}{|c|}{65 Days } \\
\hline & Control & 10 & $1.77 \pm 0.09$ & $0.14 \pm 0.03$ & $1.63 \pm 0.09$ & $0.17 \pm 0.02$ \\
\hline & Sham DRN & 16 & $1.62 \pm 0.09$ & $0.11 \pm 0.03$ & $1.71 \pm 0.08$ & $0.14 \pm 0.02$ \\
\hline & Lesion DRN & 14 & $1.71 \pm 0.13$ & $0.12 \pm 0.01$ & $1.65 \pm 0.14$ & $0.18 \pm 0.01$ \\
\hline & Sham MRN & 6 & $1.90 \pm 0.08$ & $0.09 \pm 0.07$ & $1.83 \pm 0.12$ & $0.21 \pm 0.03$ \\
\hline & Lesion MRN & 11 & $1.67 \pm 0.14$ & $0.08 \pm 0.08$ & $1.63 \pm 0.13$ & $0.16 \pm 0.02$ \\
\hline
\end{tabular}

Sham; sham operation; DRN, dorsal raphe nucleus; MRN, medial raphe nucleus; noradrenaline, NA; dopamine, DA

medial hypothalamus of animals with sham operation on the DRN (Fig. 2). Sham operation to the MRN resulted in a decrease of serotonin in the medial hypothalamus at 45 days, and an increase in the anterior hypothalamus of animals sacrificed at 65 days of age (Fig. 2).

Sham operations to the DRN or MRN did not modify the gonadotropin, progesterone, or testosterone concentrations (Table 3) or sperm concentration, viability, and motility (Table 4).

The sham operation to the DRN, in animals sacrificed at either 45 or 65 days-of-age, did not induce changes in the proportion of stages of the cycle of seminiferous epithelium (Support information 1), but changes in proportion of stages I, XI, and XII were observed between ages (Fig. 3). The area of the seminiferous epithelium (Fig. 4) and the presence of detached cells in the lumen of seminiferous tubules (Table 5), was not changed 15 or 35 days after the sham operation.

Since the sham operation in the MRN modified some the parameters analyzed in this study, the effects of lesion of the DRN or MRN were compared to their respective sham-operated group.

\section{Effects of the chemical lesion to the DRN or MRN}

No significant differences were observed in the weights of body, testis, prostate, or seminal vesicle between respective sham-operated animals and DRN or MRN lesionedanimals sacrificed at either 45 or 65 days of age (Table 1).

The chemical lesion of the DRN or MRN did not modify the noradrenaline or dopamine concentrations in the anterior and medial hypothalamus at 45 or 65 days of age (Table 2). When compared to respective sham operation, lesion of either the DRN or MRN resulted in a significant

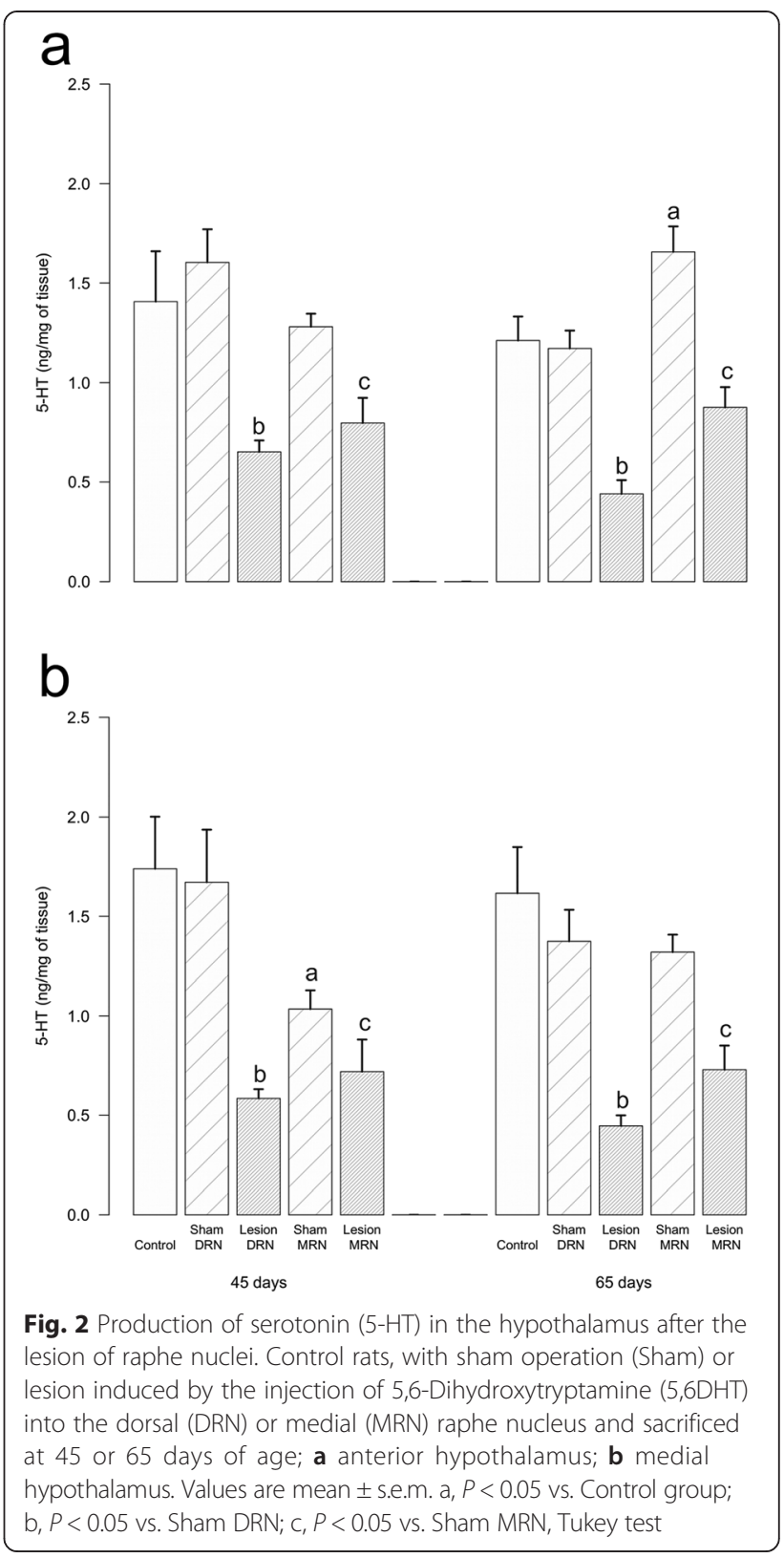

decrease in serotonin concentration in the anterior and medial hypothalamus of animals sacrificed at 45 or 65 days of age (Fig. 2).

The lesion of the DRN induced a decrease in FSH concentration in rats at 45 or 65 days of age, but the LH, progesterone, and testosterone serum concentrations were unchanged in comparison to respective sham-operated animals. No differences were observed in the FSH, LH, progesterone, and testosterone serum concentrations in the animals with a lesion of the MRN and sacrificed at 45 or 65 days of age (Table 3 ).

The chemical lesion of the DRN induced a lower sperm concentration and sperm motility, in comparison with those of the respective sham-operated group; but 
Table 3 Effects of chemical lesion of the DRN or MRN raphe nuclei on hormonal concentrations (Mean \pm S.E.M.)

\begin{tabular}{lllllll}
\hline Age at sacrifice & Group & $\mathrm{n}$ & $\mathrm{FSH}(\mathrm{ng} / \mathrm{ml}$ of serum) & $\mathrm{LH}(\mathrm{ng} / \mathrm{ml}$ of serum) & Progesterone $(\mathrm{ng} / \mathrm{ml}$ of serum) & Testosterone $(\mathrm{ng} / \mathrm{ml}$ of serum) \\
\hline 45 Days & & & & & & $0.97 \pm 0.14$ \\
& Control & 16 & $10.1 \pm 0.66$ & $0.57 \pm 0.06$ & $16.6 \pm 1.9$ & $0.68 \pm 0.10$ \\
& Sham DRN & 20 & $8.7 \pm 0.30$ & $0.37 \pm 0.05$ & $12.5 \pm 0.91$ & $0.65 \pm 0.09$ \\
& Lesion DRN & 14 & $5.9 \pm 0.87^{\mathrm{a}, \mathrm{b}}$ & $0.33 \pm 0.06$ & $10.8 \pm 1.2$ & $0.82 \pm 0.17$ \\
& Sham MRN & 11 & $9.6 \pm 0.35$ & $0.68 \pm 0.06$ & $12.4 \pm 2.1$ & $0.97 \pm 0.15$ \\
& Lesion MRN & 10 & $8.6 \pm 0.56$ & $0.59 \pm 0.08$ & $9.2 \pm 2.9$ & $2.43 \pm 0.24$ \\
& & & & & & $2.47 \pm 0.11$ \\
& Control & 22 & $8.7 \pm 0.38$ & $0.58 \pm 0.03$ & $8.0 \pm 1.1$ & $1.71 \pm 0.11$ \\
& Shams DRN & 20 & $8.2 \pm 0.30$ & $0.60 \pm 0.04$ & $9.5 \pm 1.3$ & $2.40 \pm 0.37$ \\
& Lesion DRN & 22 & $5.4 \pm 0.35^{\mathrm{a}, \mathrm{b}}$ & $0.42 \pm 0.07$ & $7.6 \pm 1.5$ & $1.54 \pm 0.31$ \\
\hline
\end{tabular}

Mean \pm s.e.m; Sham; sham operation; DRN, dorsal raphe nucleus; MRN, medial raphe nucleus ${ }^{a} p<0.05$ vs. Control group (two-way ANOVA followed by Tukey's test)

${ }^{\mathrm{b}} p<0.05$ vs. Sham DRN (two-way ANOVA followed by Tukey's test)

the chemical lesion of the MRN had no effect on these parameters (Table 4). Data of sperm concentration, motility, and viability are not presented as there were no sperm in deferens ducts at 45 days-of-age.

At the testicular level, in the animals with a chemical lesion of DRN there were no changes in proportion of stages of cycle of seminiferous epithelium at either 45 $(\mathrm{P}=0.70757)$ or 65 days-of-age $(\mathrm{P}=0.44587)$ (Additional file 1); however, when age at sacrifice was considered, deviations of independence $\left(\mathrm{P}=2.22 \times 10^{-16}\right)$ were observed at stages I, IV, VI, and XI at 45 days-of-age and I, II-III, VI, and XI at 65 days-of age (Fig. 3).

In the animals of 45 days-of-age, the area of seminiferous tubules was lower after chemical lesion of the DRN, as were stages of the cycle of seminiferous epithelium VII-XIV; however, at 65 days-of-age changes were observed only at stage VII (Fig. 4).

Each of the seminiferous tubules evaluated was searched for gross abnormalities. The abnormal presence of detached germ cells, detected in the lumen of seminiferous tubules, was significantly higher, at stages of the cycle of seminiferous epithelium VII, VIII, X and XII in animals with chemical lesion of DRN at 45 and 65 days-of-age (Table 5).

\section{Discussion}

Here we show that the serotonergic system arising from the DRN stimulates FSH secretion and testicular function, whereas the serotonergic system arising from the MRN apparently does not participate in regulation of the secretion of gonadotropins. The reproductive effects, observed 15 days after lesion of the DRN (i.e. at 45 days-of-age,), are partially alleviated at 65 days-of-age.

Our model of chemical lesion of DRN or MRN nuclei by 5,6-DHT effectively damaged serotonergic neurons. This is demonstrated by the fact that serotonin concentrations were low in the anterior and medial hypothalamus, independently of age of sacrifice, whereas noradrenaline and dopamine concentrations were unaffected. Our results are in line with previous reports $[29,40,41]$, which reported that the 5,6-DHT is easily incorporated into serotonergic neurons and has the property of autoxidation; this autoxidation generates quinones and free radicals that damage deoxyribonucleic acids, proteins, lipids, and induce the destruction of terminals and axons [40, 41].

The hypothalamus receives serotonergic innervation from the DRN and MRN [10-12]. As observed in the present study, serotonin was detected in the hypothalamus

Table 4 Effects of chemical lesion of the DRN or MRN raphe nuclei on sperm quality, of rats sacrificed at 65 days-of-age (Mean \pm S.E.M.)

\begin{tabular}{llccc}
\hline Group & $\mathrm{n}$ & Sperm concentration $\left(1 \times 10^{6}\right.$ cells/ml) & Sperm motility (\%) & Sperm viability (\%) \\
\hline Control & 22 & $71.1 \pm 4.2$ & $58.7 \pm 2.9$ & $60.9 \pm 1.4$ \\
Sham DRN & 20 & $70.2 \pm 4.8$ & $63.1 \pm 4.7$ & $58.2 \pm 2.7$ \\
Lesion DRN & 22 & $41.2 \pm 2.8^{*}$ & $39.6 \pm 4.4^{*}$ & $52.1 \pm 3.5$ \\
Sham MRN & 10 & $67.0 \pm 2.8$ & $55.0 \pm 2.3$ & $57.2 \pm 1.8$ \\
Lesion MRN & 15 & $71.3 \pm 2.7$ & $50.4 \pm 2.0$ & $61.7 \pm 2.0$ \\
\hline
\end{tabular}

Mean \pm s.e.m; Sham; sham operation; DRN, dorsal raphe nucleus; MRN, medial raphe nucleus ${ }^{*} p<0.05$ vs. Sham DRN (Two way ANOVA followed by Tukey 's test) 


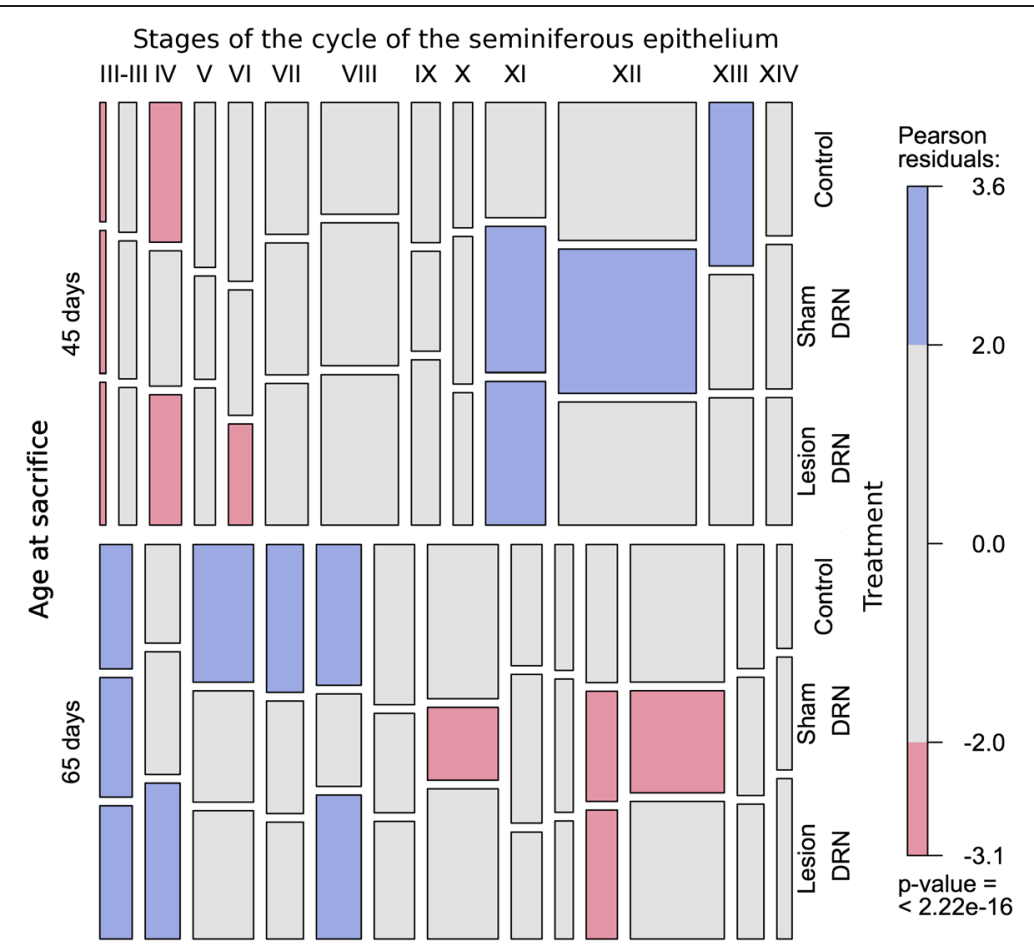

Fig. 3 The lesion in the DRN induced changes in the proportions of stages of the cycle of seminiferous epithelium at 45 or 65 days-of age. Mosaic plot for stages of the cycle of seminiferous epithelium, treatment, and age at sacrifice. In the mosaic plot each cell of a contingency table is represented by a rectangle whose area shows the cell frequency or deviation from independence (Friendly, 1994). The area of each cell is proportional to cell frequency. Cells with positive, negative, or no deviation from independence are filled with blue, red, or gray color, respectively (Please see the look up table at right side of the mosaic)

of animals with chemical lesion of the DRN or MRN, indicating that the production of serotonin was not completely eliminated in either group. These results are similar to those reported when a higher dose of the same drug was injected intraventricularly into prepuberal male rats [42]. Two possibilities could explain the presence of serotonin in the hypothalamus of the lesioned animals. First, because we only introduced lesions in DRN or MRN, the presence of the remaining nucleus could be a source of serotonin in the hypothalamus. Second, neurons located in the hypothalamus could produce serotonin, as previously published [reviewed in 20].

The decrease of 5-HT concentration in the hypothalamus of animals with a lesion of the DRN or MRN was maintained from 45 until 65 days-of-age. This results are in line with two facts: 1) 5,6-DHT induce degeneration of serotonergic fibers [43], and 2) degeneration of serotonergic fibers persisted from two weeks to one month [29, 42, 43].

The mechanism by which the MRN sham operation modified the serotonin concentration in the hypothalamus is unknown. This effect could be related with the sectioning of serotonergic fibers, during the introduction of the injection needle. Serotonergic projections of MRN to the ventromedial hypothalamus and preoptic area contain fibers, arising from the left and right side of the nucleus [12]. In all animals with MRN sham operation the needle of microinjection was introduced by the right side. Then, it is possible that the changes in serotonin concentration are related to the surgical trauma of right fibers induced by introduction of the injection needle, and the hyperactivity of undamaged left projections arising from the nucleus.

In the present study, the interruption of serotonergic communication between the DRN and the anterior and medial hypothalamus diminished the concentrations of FSH at 45 and 65 days-of-age. The lack of serotonergic innervation arising from the MRN, did not have an effect on gonadotropin secretion. On this basis, we suggest the existence of two serotonergic systems: a first serotonergic system, arising from the DRN, which innervates the preoptic area, stimulates FSH secretion and sperm production, and does not affect LH secretion; whereas, the second serotonergic system, arising from the MRN, and the main source of serotonin in the mediobasal hypothalamus, does not participate in gonadotropin secretion. This differential effect could-be related to two gonadotropin releasing factors, one for FSH and another for LH, whose existence was previously suggested $[44,45]$. 

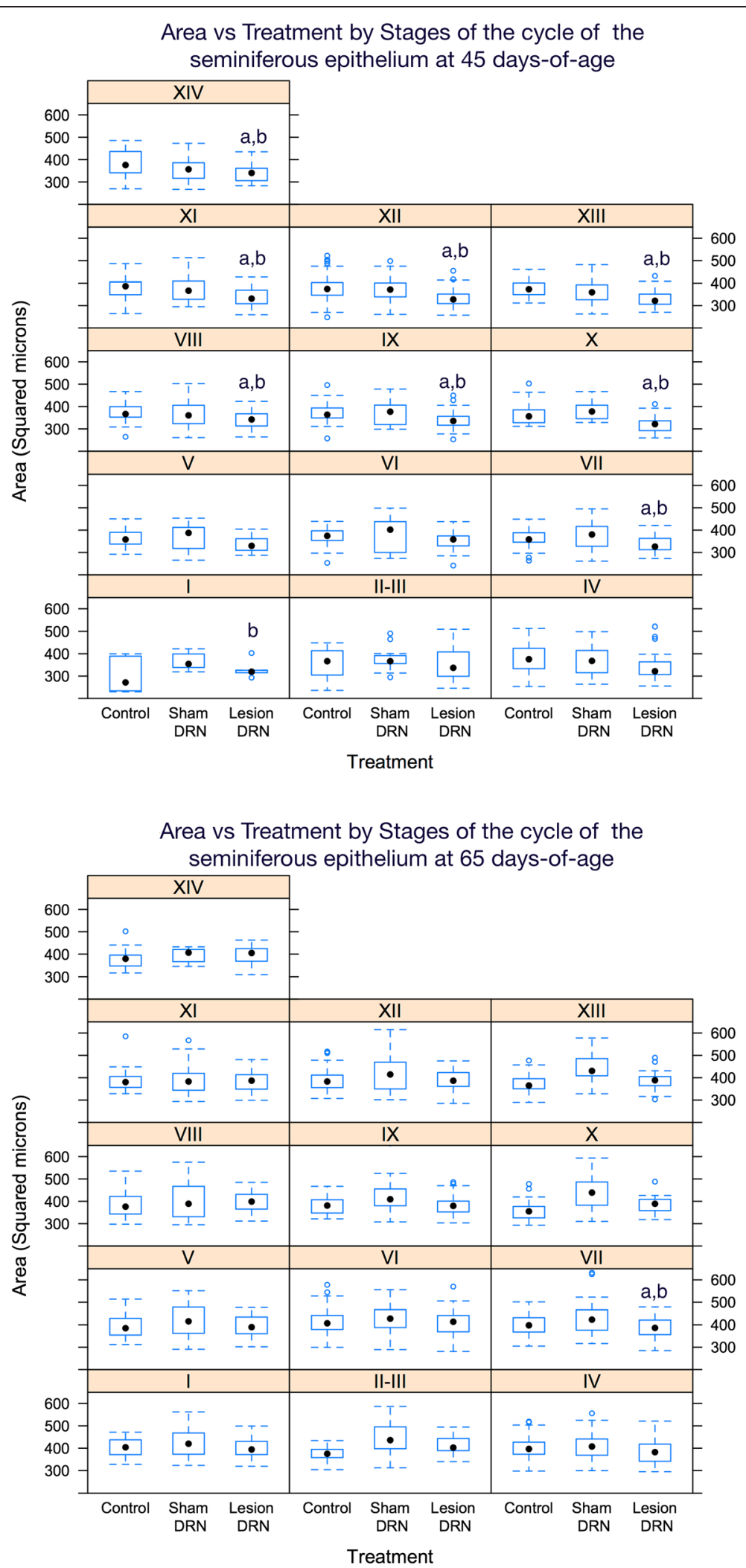

Fig. 4 The area of seminiferous tubules is modified by lesion of the DRN at specific stages of the cycle of the seminiferous epithelium. Values are medians (horizontal bar in boxes) with $25 \%-75 \%$ interquartile ranges (boxes); dotted vertical lines indicate minimum and maximum values; circles indicate outliers. ${ }^{\mathrm{a}} \mathrm{P}<0.05$ vs Control; ${ }^{\mathrm{b}} \mathrm{P}<0.05$ vs Sham DRN 
Table 5 The presence of detached germ cells into the lumen of seminiferous tubules is stage-dependent. Mean number of tubules with germ cells into the lumen 15 or 35 days after the lesion of the DRN (Mean \pm S.E.M.)

\begin{tabular}{|c|c|c|c|c|c|}
\hline \multirow[b]{2}{*}{ Age at sacrifice } & \multirow[b]{2}{*}{ Group } & \multicolumn{4}{|c|}{ Stages of the cycle of the seminiferous epitheliun } \\
\hline & & $\mathrm{VII}$ & VIII & $x$ & $X \|$ \\
\hline \multicolumn{6}{|l|}{45 Days } \\
\hline & Control & 0 & $1.0 \pm 0.3$ & $0.2 \pm 0.1$ & $1.6 \pm 0.1$ \\
\hline & Sham DRN & $1.4 \pm 0.5$ & $2.0 \pm 0.6$ & $0.4 \pm 0.2$ & $2.2 \pm 0.5$ \\
\hline & Lesion DRN & $5.8 \pm 1.0^{b}$ & $11.0 \pm 0.7^{\mathrm{a}, \mathrm{b}}$ & $0.8 \pm 0.4$ & $3.8 \pm 0.5$ \\
\hline \multicolumn{6}{|l|}{65 Days } \\
\hline & Control & $0.2 \pm 0.0$ & $1.2 \pm 0.5$ & 0 & $0.8 \pm 0.0$ \\
\hline & Sham DRN & $0.8 \pm 0.5$ & $2.0 \pm 0.1$ & $0.3 \pm 0.1$ & $1.2 \pm 0.4$ \\
\hline & Lesion DRN & $7.0 \pm 0.9^{\mathrm{a}, \mathrm{b}}$ & $11.2 \pm 1.6^{\mathrm{a}, \mathrm{b}}$ & $1.4 \pm 0.2^{\mathrm{a}, \mathrm{b}}$ & $7.6 \pm 1.1^{\mathrm{a}, \mathrm{b}}$ \\
\hline
\end{tabular}

Sham; sham operation; DRN, dorsal raphe nucleus

${ }^{\mathrm{a} P}<0.05$ vs. Control; ${ }^{\mathrm{b}} \mathrm{P}<0.05$ vs. Sham DRN (Two way ANOVA followed by Tukey 's test)

Our idea, that the serotonergic system arising from the DRN participates in the modulation of secretion of FSH, is supported by results of a previous report [46], where the treatment of prepuberal male rats with 5hydroxytryptophan (5-HTP) leads to an increase in serotonin concentration in the hypothalamus and FSH in serum. In the preoptic area, there is communication between serotonergic terminals and GnRH neurons [13, $47,48]$. Also, serotonin in the preoptic area stimulates FSH secretion, which is mediated by the 5-HT2 receptor [49]. The GnRH neurons of mouse have several different serotonin receptors: 5-HT1A, 5-HT3A, and 5-HT4 [50]. Collectively, these studies and our results support the idea that the decrease of FSH induced by the lesion of the DRN leads to the modification of the neuroendocrine mechanism that regulates FSH secretion.

An alternative explanation for the low concentrations of FSH observed in the animals with DNR lesion is that the lack of DRN serotonergic innervation results in the activation of other neural pathways participating in the control of gonadotropin secretion. We suggest that this neural pathway is the serotonergic innervation arising from the MRN; this suggestion is supported by the fact that serotonergic innervation arising from the MRN inhibits the secretion of gonadotropins in the female rat $[3,5]$. The DRN and MRN nuclei are anatomically connected [22]; thus, it is possible that the DRN controls the functions of the MRN, as previously suggested [23].

The decrease in sperm count and FSH concentrations observed in our work after chemical lesion of the DRN is in line with reports that support the role of FSH as a factor of germ cell proliferation [51-54]. In the case of prepuberal-pubertal male rat, FSH increases between 30 and 40 days-of-age [55]. FSH is involved in the initiation and maintenance of spermatogenesis; in prepuberal rats, FSH acts in Sertoli cells, and stimulates the secretion of growth factors essential for proliferation and differentiation of germ cells $[51,53,54]$. The decrease of FSH concentrations, induced by hypophysectomy in prepuberal male rats, induces the degeneration of pachytene spermatocytes, secondary spermatocytes, and round spermatids; whereas the treatment of these animals with FSH or FSH plus LH decreased the degeneration of germ cells $[52,56]$. The studies mentioned and our results support the idea that the diminution of FSH concentration, induced by the chemical lesion of DRN, has a role in decreasing sperm production.

Spermatogenesis is a multi-factorial regulated process that involves the participation of gonadotropins and androgens, among other factors [51-54, 56]. The results presented herein show that the decreases in the spermatogenesis induced by the lesion of the DRN did not correlate with changes in testosterone levels. This result indicates that factors other than testosterone participate in the modulation of spermatogenesis. One such factor is FSH, which has been previously indicated [54]. Another possibility is that the diminution of FSH concentrations in the animals with a lesion on the DRN could affect the Sertoli cell functions and spermatogenesis. Both testosterone and FSH have a synergistic action on Sertoli cells to maintain spermatogenesis [54]. The action of these hormones is mediated through receptors [57], and FSH facilitates the synthesis of androgen protein binding in Sertoli cells [54, 57]. FSH, together with testosterone, prevents apoptosis and promotes the survival of germ cells, mainly spermatocytes and round spermatids, and are involved in spermiation $[51,53]$. Accordingly, this evidence supports the interaction of testosterone and FSH with Sertoli Cells for regulation of spermatogenesis. Based on these lines of evidence, it is possible that the decrease in spermatogenesis in the animals with a lesion in the DRN is related to the diminished action of testosterone, mediated in turn by the diminution on FSH secretion.

The fact that, in the animals with lesion of the MRN, FSH and testosterone concentrations were similar to those observed in the respective sham operated group, indicates 
that concentrations of these hormones were sufficient to maintain the spermatogenesis.

The fact that, 35 days after the lesion of the MRN, the concentrations of FSH and sperm traits were not altered, indicates that the serotonergic system arising from the MRN, is not involved in the regulation of FSH secretion and spermatogenesis. Possibly, the lack of serotonergic innervation arising in the MRN, is compensated by the presence of serotonergic system arising from the DRN, which exerts a stimulatory role on secretion of FSH and spermatogenesis. This idea is supported by the existence of a neural connection between the DRN and MRN, as previously proposed [22].

The testicular effects of lesion of the DRN are transient. The opposite pattern of proportion of stages of cycle of seminiferous epithelium, with positive or negative deviations of independence, between animals of 45 and 65-daysof-age, and the higher values of the area of seminiferous tubules at 65 days-of-age, indicates the progression of the testicular development. This assumption is supported by the increase in weight of the testis and accessory glands in animals with lesion of the DRN at 65 days-of-age compared with those of 45-days-of-age.

The lesion of the DRN did not affect the concentrations of either LH or sexual steroids. This indicates that functionality of Leydig cells was not altered. Previous evidence supports this assertion that, in the rat, testosterone synthesis occurs mainly in the testis and secretion by the adrenal gland is limited, since the removal of testis resulted in lower testosterone serum levels and adrenalectomy did not modify testosterone serum levels [58].

Together our results show that serotonin arising from the DRN is involved in the modulation of the testis function. Thus the drugs that enhance or inhibit serotonin activity may have implications on reproduction. The use of antidepressants such as selective serotonin reuptake inhibitors (SSRI) induce negative reproductive effects in adult men [59], in woman during pregnancy [60], and male exposed in utero [61]. SSRI and are widely prescribed for children and adolescents, although data regarding their safety are limited [62]. Recently, a detailed description of disruption of the axis hypothalamus-hypophysis-testicle by SSRI was described in mature male zebrafish (Prasad et al., in press [63]), but information on mammal models is still scarce.

\section{Conclusions}

Here we demonstrate that serotonergic system, arising from the DRN and MRN, participates differentially in the modulation of the neuroendocrine mechanisms that regulate testicular function. In light of our results, the use of prescription or abuse drugs which affect the serotonergic system, could impact the activity of DRN and MRN nuclei, and thus affect the male reproductive function.

\section{Additional file}

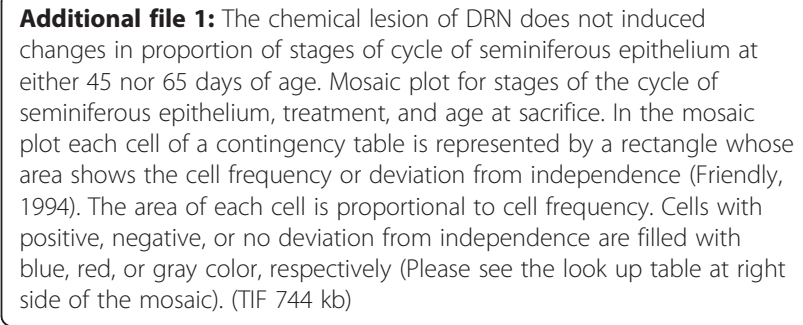

\section{Competing interests}

The authors declare that they have no competing interests.

\section{Authors' contributions}

MEA and AA conceived all of the experiments. DEV, JLM, JM, RD, MC, MEA and AA carried out all of the experiments, participated in the analysis and discussion of the results. JM and MC measured hormones by RIA. The manuscript was prepared by MEA and AA. All authors critically revised the manuscript and approved the final version.

\section{Acknowledgements}

This work was supported by DGPA-UNAM grant IN223714. The gift of reagents for FSH and LH RIA measurements by the National Institute of Health is gratefully acknowledged.

\section{Author details}

'Unidad de Investigación en Biología de la Reproducción, Laboratorio de Pubertad, Facultad de Estudios Superiores Zaragoza, UNAM. AP 9-020, CP 15000, Distrito Federal, México. ${ }^{2}$ Laboratorio de Hormonas Proteicas, Instituto de Ciencias Médicas y de la Salud Salvador Subirán, Tlalpan, CP 14000 México, D.F., México. ${ }^{3}$ Ciencia, Tecnología e Informática Aplicadas a la Reproducción S A, Texcoco, CP 56200, Estado de México, México. ${ }^{4}$ Instituto Tecnológico del Altiplano de Tlaxcala, San Diego Xocoyucan, CP 90122, Tlaxcala, México.

Received: 22 July 2015 Accepted: 18 September 2015 Published online: 08 December 2015

\section{References}

1. Ulloa-Aguirre A, Timossi C. Biochemical and functional aspects of gonadotrophin-releasing hormone and gonadotrophins. Reprod Biomed Online. 2000;1:48-62.

2. Herbison AE. Physiology of the gonadotropin-releasing hormone neuronal network. In: Knobil E, Neill JD, editors. The Physiology of Reproduction. 3rd ed. New York: Elsevier, Inc; 2006. p. 1415-82.

3. Morello $\mathrm{H}$, Taleisnik S. Changes of the release of luteinizing hormone $(\mathrm{LH})$ on the day of proestrus after lesions or stimulation of the raphe nuclei in rats. Brain Res, 1985;360:311-7.

4. Morello H, Taleisnik S. The inhibition of proestrous LH surge and ovulation in rats bearing lesions of the dorsal raphe nucleus is mediated by the locus coeruleus. Brain Res. 1988:440:227-31.

5. Morello H, Caligaris L, Haymal B, Taleisnik S. Further evidence of an opposite effect of dorsal and median raphe nuclei on the proestrous surge of $\mathrm{LH}$. Acta Endocrinol (Copenh). 1990;122:696-702.

6. Monroy J, Ayala ME, Chavira R, Damián-Matsumura P, Domínguez R. Comparative effects of injecting 5,6-dihydroxytryptamine in the dorsal or medial raphe nuclei on rat puberty. Brain Res Bull. 2003;60:307-15.

7. Héry M, Laplante E, Kordon C. Participation of serotonin in the phasic release of luteinizing hormone. II. Effects of lesions of serotonin-containing pathways in the central nervous system. Endocrinology. 1978;102:1019-25.

8. Van de Kar LD, Lorens SA. Differential serotonergic innervation of individual hypothalamic nuclei and other forebrain regions by the dorsal and median midbrain raphe nuclei. Brain Res. 1979;162:45-54. 
9. Van de Kar LD, Lorens SA, Vodraska A, Allers G, Green M, Van Orden DE, et al. Effect of selective midbrain and diencephalic 5,7-dihydroxytryptamine lesions on serotonin content in individual preopticohypothalamic nuclei and on serum luteinizing hormone level. Neuroendocrinology. 1980;31:309-15.

10. Peyron C, Petit JM, Rampon C, Jouvet M, Luppi PH. Forebrain afferents to the rat dorsal raphe nucleus demonstrated by retrograde and anterograde tracing methods. Neuroscience. 1998;82:443-68.

11. Azmitia EC, Whitaker-Azmitia O. Development and adult plasticity of serotoninergic neurons and their target cells. In: Baumgarten H, Göthert M Baumgarten H, Göthert M, editors. Serotoninergic Neurons and 5-HT Receptors in the CNS. Berlin, Germany: Springer Verlag; 2000. p. 1-39.

12. Kanno K, Shima S, Ishida Y, Yamanouchi K. Ipsilateral and contralateral serotonergic projections from dorsal and median raphe nuclei to the forebrain in rats: immunofluorescence quantitative analysis. Neurosci Res. 2008;61:207-18.

13. Jennes L, Beckman WC, Stumpf WE, Grzanna R. Anatomical relationships of serotoninergic and noradrenalinergic projections with the $\mathrm{GnRH}$ system in septum and hypothalamus. Exp Brain Res Exp Hirnforsch Expérimentation Cérébrale. 1982;46:331-8.

14. Jennes L, Stumpf WE, Tappaz ML. Anatomical relationships of dopaminergic and GABAergic systems with the GnRH-systems in the septo-hypothalamic area, Immunohistochemical studies. Exp Brain Res. 1983;50:91-9.

15. Kordon C, Drouva S, Martínez De La Escalera G. Weiner R. Role of classic and peptide neuromediators in the neuroendocrine regulation on luteinizing hormone and prolactin. In: Knobil E, Neill JD, editors. The Physiology of Reproduction. Volume 1. 3rd ed. New York: Elsevier, Inc; 2006. p. 1621-81.

16. Marinelli S, Schnell SA, Hack SP, Christie MJ, Wessendorf MW, Vaughan CW. Serotonergic and nonserotonergic dorsal raphe neurons are pharmacologically and electrophysiologically heterogeneous. J Neurophysiol. 2004;92:3532-7.

17. Monti JM. The structure of the dorsal raphe nucleus and its relevance to the regulation of sleep and wakefulness. Sleep Med Rev. 2010;14:307-17.

18. Calizo LH, Akanwa A, Ma X, Pan Y, Lemos JC, Craige C, et al. Raphe serotonin neurons are not homogenous: Electrophysiological, morphological and neurochemical evidence. Neuropharmacology. 2011;61:524-43.

19. Nobin A, Björklund A. Degenerative effects of various neurotoxic indoleamines on central monoamine neurons. Ann N Y Acad Sci. 1978;305:305-27.

20. Takeuchi Y. Distribution of serotonin neurons in the mammalian brain. In: Osborne N, editor. Neuronal Serotonin. New York, USA: John Wiley and Sons, Ltd; 1988. p. 25-56.

21. Mamounas LA, Mullen CA, O'Hearn E, Molliver ME. Dual serotoninergic projections to forebrain in the rat: morphologically distinct 5-HT axon terminals exhibit differential vulnerability to neurotoxic amphetamine derivatives. J Comp Neurol. 1991;314:558-86.

22. Vertes RP, Fortin WJ, Crane AM. Projections of the median raphe nucleus in the rat. J Comp Neurol. 1999:407:555-82.

23. Mokler DJ, Dugal JR, Hoffman JM, Morgane PJ. Functional interrelations between nucleus raphé dorsalis and nucleus raphé medianus: a dual probe microdialysis study of glutamate-stimulated serotonin release. Brain Res Bull. 2009;78:132-8.

24. Molliver ME, Berger UV, Mamounas LA, Molliver DC, O'Hearn E, Wilson MA. Neurotoxicity of MDMA and related compounds: anatomic studies. Ann N Y Acad Sci. 1990;600:649-64.

25. Commins DL, Axt KJ, Vosmer G, Seiden LS. 5,6-Dihydroxytryptamine, a serotonergic neurotoxin, is formed endogenously in the rat brain. Brain Res. 1987:403:7-14.

26. Commins DL, Axt KJ, Vosmer G, Seiden LS. Endogenously produced 5,6dihydroxytryptamine may mediate the neurotoxic effects of parachloroamphetamine. Brain Res. 1987:419:253-61.

27. Wrona MZ, Yang Z, Zhang F, Dryhurst G. Potential new insights into the molecular mechanisms of methamphetamine-induced neurodegeneration. NIDA Res Monogr. 1997;173:146-74

28. Paxinos G, Watson C. The Rat Brain in Stereotaxic Coordinates. New York, USA: Academic Press; 2007

29. Baumgarten HG, Björklund A, Lachenmayer L, Nobin A, Stenevi U. Long-lasting selective depletion of brain serotonin by 5,6-dihydroxytryptamine. Acta Physiol Scand Suppl. 1971:373:1-15.

30. Linder RE, Strader LF, Slott VL, Suarez JD. Endpoints of spermatotoxicity in the rat after short duration exposures to fourteen reproductive toxicants. Reprod Toxicol. 1992;6:491-505.

31. Seed J, Chapin RE, Clegg ED, Dostal LA, Foote RH, Hurtt ME, et al. Methods for assessing sperm motility, morphology, and counts in the rat, rabbit, and dog: a consensus report. ILSI Risk Science Institute Expert Working Group on Sperm Evaluation. Reprod Toxicol. 1996;10:237-44.

32. Russell LD, Ettlin RA, Sinha Hikim AP, Clegg ED. Histological and Histopathological Evaluation of the Testis. Clearwater, FL, USA: Cache River Press; 1990.

33. Team RDC. R: A Language and Environment for Statistical Computing. Vienna: Austria; 2011

34. Fox J. Weisberg: Companion to Applied Regression. 2nd ed. Thousand Oaks, CA, USA: Sage; 2011.

35. Meyer D, Zeileis A, Hornik K. The strucplot framework: visualizing multi-way contingency tables with ved. J Satistical Softw. 2006;17:1-48.

36. Meyer D, Zeileis A, Hornik K. Vcd: Visualizing Categorical Data. Thousand Oak, CA, USA: Sage; 2014

37. Zeileis A, Meyer D, Hornik K. Residual-based shadings for visualizing (conditional) independence. J Comput Graph Stat. 2007;16:507-25.

38. Graham GJ. Data Mining with Rattle and R: The Art of Excavating Data for Knowledge Discovery. New York, USA: Springer; 2011 [Use R!].

39. Deepayan S. Lattice: Multivartiate Data Visualization with R. New York, USA Springer; 2008 [Use R!]

40. Sinhababu AK, Ghosh AK, Borchardt RT. Molecular mechanism of action of 5,6-dihydroxytryptamine. Synthesis and biological evaluation of 4-methyl-, 7-methyl-, and 4,7-dimethyl-5,6-dihydroxytryptamines. J Med Chem. 1985;28: 1273-9.

41. Singh S, Dryhurst G. Further insights into the oxidation chemistry and biochemistry of the serotonergic neurotoxin 5,6-dihydroxytryptamine. J Med Chem. 1990;33:3035-44.

42. Collu R. Endocrine effects of brain serotonin depletion by 5,6dihydroxytryptamine in prepubertal male rats. Ann N Y Acad Sci. 1978;305:411-22.

43. Ueda S, Kawata M. Regeneration of serotonergic immunoreactive fibers in the brain of 5,6-dihydroxytryptamine treated rat. J Für Hirnforsch. 1994;35:159-80

44. Culler MD, Negro-Vilar A. Evidence that pulsatile follicle-stimulating hormone secretion is independent of endogenous luteinizing hormone-releasing hormone. Endocrinology. 1986;118:609-12.

45. McCann SM, Karanth S, Mastronardi CA, Dees WL, Childs G, Miller B, et al Control of gonadotropin secretion by follicle-stimulating hormone-releasing factor, luteinizing hormone-releasing hormone, and leptin. Arch Med Res. 2001;32:476-85.

46. Justo SN, Rossano GL, Szwarcfarb B, Rubio MC, Moguilevsky JA. Effect of serotoninergic system on FSH secretion in male and female rats: evidence for stimulatory and inhibitory actions. Neuroendocrinology. 1989;50:382-6.

47. Villar MJ, Chiocchio SR, Tramezzani JH. Origin and termination of dorsal raphe-median eminence projection. Brain Res. 1984;324:165-70.

48. Kiss J, Halász B. Demonstration of serotoninergic axons terminating on luteinizing hormone-releasing hormone neurons in the preoptic area of the rat using a combination of immunocytochemistry and high resolution autoradiography. Neuroscience. 1985;14:69-78.

49. Gouveia EM, Franci CR. Involvement of serotonin $5 \mathrm{HT} 1$ and $5 \mathrm{HT} 2$ receptors and nitric oxide synthase in the medial preoptic area on gonadotropin secretion. Brain Res Bull. 2004;63:243-51

50. Todman MG, Han S-K, Herbison AE. Profiling neurotransmitter receptor expression in mouse gonadotropin-releasing hormone neurons using green fluorescent protein-promoter transgenics and microarrays. Neuroscience. 2005;132:703-12

51. Sofikitis N, Giotitsas N, Tsounapi P, Baltogiannis D, Giannakis D, Pardalidis N Hormonal regulation of spermatogenesis and spermiogenesis. J Steroid Biochem Mol Biol. 2008;109:323-30.

52. Russell LD, Kershaw M, Borg KE, El Shennawy A, Rulli SS, Gates RJ, et al. Hormonal regulation of spermatogenesis in the hypophysectomized rat: FSH maintenance of cellular viability during pubertal spermatogenesis. J Androl. 1998;19:308-19.

53. Ruwanpura SM, McLachlan Rl, Meachem SJ. Hormonal regulation of male germ cell development. J Endocrinol. 2010;205:117-31.

54. Alves MG, Rato L, Carvalho RA, Moreira PI, Socorro S, Oliveira PF. Hormonal control of Sertoli cell metabolism regulates spermatogenesis. Cell Mol Life Sci. 2013;70:777-93.

55. Ojeda SR, Skinner MK. Puberty in the rat. In: Knobil E, Neill JD, editors. The Physiology of Reproduction. 3rd ed. New York: Elsevier, Inc; 2006. p. 2061-126.

56. Weinbauer GF, Nieschlag E. Hormonal control of spermatogenesis. In: de Kretser DM, editor. Molecular Biology of the Male Reproductive System. San Diego, USA: Academic Press; 1993. p. 99-141. 
57. Chang C, Chen Y-T, Yeh S-D, Xu Q, Wang R-S, Guillou F, et al. Infertility with defective spermatogenesis and hypotestosteronemia in male mice lacking the androgen receptor in Sertoli cells. Proc Natl Acad Sci U S A. 2004;101:6876-81.

58. Stahl F, Götz F, Dörner G. Plasma testosterone levels in rats under various conditions. Exp Clin Endocrinol. 1984;84:277-84.

59. Tanrikut C, Feldman AS, Altemus M, Paduch DA, Schlegel PN. Adverse effect of paroxetine on sperm. Fertil Steril. 2010;94:1021-6.

60. Domar AD, Moragianni VA, Ryley DA, Urato AC. The risks of selective serotonin reuptake inhibitor use in infertile women: a review of the impact on fertility, pregnancy, neonatal health and beyond. Hum Reprod. 2013;28:160-71.

61. Ramos AC, H Dos Santos A, Silveira KM, Kiss ACI, Mesquita SFP, Gerardin DCC. Maternal treatment with fluoxetine promotes testicular alteration in male rat pups. Reprod Fertil Dev. 2015. doi:10.1071/RD14199.

62. Weller EB, Tucker $\mathrm{S}$, Weller RA. The selective serotonin reuptake inhibitors controversy in the treatment of depression in children. Curr Psychiatry Rep. 2005;7:87-90.

63. Prasad P, Ogawa S, Parhar IS: Serotonin Reuptake Inhibitor Citalopram Inhibits GnRH synthesis and Spermatogenesis in the Male Zebrafish. Biol Reprod 2015. 10.1095/biolreprod.115.129965.

\section{Submit your next manuscript to BioMed Central and take full advantage of:}

- Convenient online submission

- Thorough peer review

- No space constraints or color figure charges

- Immediate publication on acceptance

- Inclusion in PubMed, CAS, Scopus and Google Scholar

- Research which is freely available for redistribution 